\title{
Identidade Negra entre exclusão e liberdade
}

\author{
[ Black Identity between exclusion and freedom
}

\author{
Viviane Barboza Fernandes ${ }^{\mathrm{I}}$
}

\section{Maria Cecilia Cortez Christiano de Souza ${ }^{2}$}

\begin{abstract}
RESUMO - No presente trabalho apresentamos algumas reflexões sobre a influência de marcadores sociais na representação social do negro. Discutimos as consequências desses constructos sociais em torno do "corpo negro", assim como suas implicações na construção da identidade negra no Brasil. Além disso, apontamos brevemente a importância das ações do movimento negro no campo educacional na luta e conquista de políticas públicas, como a lei n. 10.639/2003. Sob essa perspectiva, falamos da contribuição da educação na desconstrução de estereótipos, assim como da importância das africanidades na criação de possibilidades de intervenção no processo de formação identitária, para que as narrativas dominantes sobre o "ser negro" sejam desafiadas e se construa um espaço educativo de ressonância a histórias e identidades marginalizadas. • PALAVRASCHAVE - identidade negra; marcadores sociais; representação social; africanidades; educação - ABSTRACT • In this paper, we
\end{abstract}

Recebido em 23 de março de 2015

Aprovado em 26 de fevereiro de 2016

DOI: http://dx.doi.org/Io.II6o6/issn.23I6-90IX.voi63pI03-I20

I Universidade de São Paulo (USP, São Paulo, SP, Brasil)

2 Universidade de São Paulo (USP, São Paulo, SP, Brasil) present some reflections on the influence of social markers in the social representation of Black People. We discuss the consequences of these social constructs about the "black body", as well as their implication for the construction of black identity in Brazil. In addition, it is briefly pointed out the importance of the actions of the Black Movement in the educational field to the struggle for implement public policies like the Law Io.639/2003. From this perspective, the contribution of education in the deconstruction of stereotypes is pointed, as well as the importance of Africanities to create intervention possibilities in the identity formation process so that the dominant narratives about "how to be Black" can be challenged and help to build an educational environment to resound histories and marginalized identities. - KEYWORDS - black identity; social markers; social representation; africanities; education 


\section{IDENTIDADE E REPRESENTAÇÕES SOCIAIS SOBRE O CORPO NEGRO}

As relações étnico-raciais são formadas historicamente mediante a construção de imagens e representações sociais. Como diz Stuart Hall,

A representação é o processo pelo qual membros de uma cultura usam a linguagem para instituir significados. Essa definição carrega uma premissa: as coisas, os objetos, os eventos do mundo não têm, neles mesmos, qualquer sentido fixo, final ou verdadeiro. Somos nós, em sociedade, entre culturas humanas, que atribuímos sentidos às coisas. Os sentidos, consequentemente, sempre mudarão de uma cultura para outra e de uma época para outra3.

As representações de todos os grupos sociais circulam no meio social produzindo sentidos e consequências. No entanto, algumas representações ganham maior visibilidade e passam a ser consideradas como expressão da realidade social ${ }^{4} \mathrm{Na}$ sociedade brasileira, assim como em outras, as representações que prevalecem são construídas por narrativas hegemônicas, capazes de representar um grupo social em detrimento de outros. Essas representações foram construídas mediante a óptica eurocêntrica, que institui sentidos de "normalidade" e "anormalidade", estabelecendo como norma padrão o homem, branco, heterossexual, cristão. Os indivíduos que não correspondem a esse padrão são vistos como desviantes, abjetos, e excluídos socialmente. Conforme afirma Judith Butler,

O abjeto designa aqui precisamente aquelas zonas "inóspitas" e "inabitáveis" da vida social, que são, não obstante, densamente povoadas por aqueles que não gozam do

3 HALL, Stuart. The Work of Representation. In: . Representation, Cultural Representations and Signifying Practices. Londres/Nova Deli: Thousands Oaks/Sage, I997, p. 6I.

4 LOURO, Guacira Lopes. Pedagogias da sexualidade. In: . O corpo educado: Pedagogias da sexualidade. Belo Horizonte: Autêntica, 2000, p. 9. 
status de sujeito, mas cujo habitar sob o signo do “inabitável” é necessário para que o domínio do sujeito seja circunscrito5.

A abjeção social decorre da criação de "marcadores sociais" que, formulados a partir de teorias biológicas errôneas, fazem das marcas corporais elementos através dos quais se pode homogeneizar os sujeitos e naturalizar identidades. A reificação de que era objeto o africano escravizado e seus descendentes foi metamorfoseada, no fim do século XIX e início do XX, em teorias racistas que tiveram por base aquilo que na época era considerado biologia científica ${ }^{6}$. A ideia de raça dos sujeitos passou a ser deduzida por meio dessas marcas corporais, dedução que resultou na essencialização das identidades.

Estas formulações correspondem a uma visão equivocada sobre o corpo, pois a identidade não pode ser considerada como decorrente das "evidências" corporais7. Pois mesmo nas ideologias racista há nuances: o que é definido como negro ou branco no Brasil, não o é da mesma forma nos Estados Unidos ou na África do Sul. De um modo ou outro, no entanto, para as ideologias racistas "o corpo é visto como a corte de julgamento final sobre o que somos ou o que podemos nos tornar"8. No entanto, como Guacira Lopes Louro ressalta, o corpo não tem uma concepção estática, uma vez que ele é significado e alterado constantemente pela cultura. Essa tentativa de apreensão rígida ligada às teorias pseudocientíficas do racismo está relacionada,

5 BUTLER, Judith. Corpos que pesam: sobre os limites discursivos do “sexo”. In: LOURO, Guacira Lopes (org.). O corpo educado. Pedagogias da sexualidade. Belo Horizonte: Autêntica, 2000, p. I55.

6 Nunca é demais assinalar que tanto para o Movimento Negro quanto para a sociologia e a antropologia que se debruça sobre o tema, a palavra "raça” não se refere ao conceito biológico de raças humanas, amplamente rechaçado pelo conhecimento científico hoje vigente. Tal conceito se refere à construção social que reúne em si características físicas (percebidas culturalmente) e dados culturais. Este último conceito de raça, relacionado à identidade negra, foi reinvindicação do Movimento Negro Unificado (MNU) no Brasil. O MNU defendeu tal posição quando surgiu como interlocutor político importante no final dos anos 1970, na luta pela derrubada no regime militar. Durante os anos de ditadura, falar da questão racial era considerado impatriótico, alvo de repressão e o dado "raça" retirado de pesquisas oficiais. O MNU considerou como negros, além dos pretos, os que antes eram classificados como "pardos". Nessa mesma época, de forma independente, no plano das ciências sociais, os trabalhos de Carlos Hasenbalg, de I979, e de Nelson do Valle e Silva, de I980, mostraram, inequivocamente, com base nos dados do IBGE, as desigualdades econômicas e sociais existentes entre brancos e negros, ou seja, entre brancos e aqueles que se autodefinem como pretos e pardos. A partir desses trabalhos, essas diferenças não puderam mais ser explicadas por conjunturas históricas resultantes do escravismo nem como meras diferenças econômicas e políticas capazes de serem subsumidas a diferenças de classe de renda. No plano político, o MNU ressignificou o termo raça, inclusive para combater o racismo, forjando nova conotação para o conceito de identidade negra, ligando-a à cultura e ao restabelecimento da memória histórica da diáspora africana. No plano as ciências sociais, o termo raça foi adotado para designar as diferenças de oportunidades de vida, de cultura e de formas de tratamento peculiares ao grupo de afrodescendentes, daí por diante chamados de negros. Cf. GUIMARÃES, Antônio Sergio Alfredo. Como trabalhar com "raça" em Sociologia. Educação e Pesquisa, vol. 29, n. I, p. 93-I07, 2003.

7 LOURO, Guacira Lopes. Op. cit., p. 8.

8 Idem, ibidem. 
segundo alguns autores, ao desejo de fixação da identidade em face da angústia que é sentida diante de incertezas e de ameaça de dissolução?.

Avtar Brah ${ }^{\mathrm{Io}}$ relaciona esses marcadores sociais a "diferenças", ou seja, a marcas produtoras de diferenciação social, que estabelecem lugares distintos para os sujeitos dentro da estrutura social. Para Stuart Hall, esses marcadores caracterizam "unidades" que resultam de um processo de naturalização e fechamento a partir do contraste entre os termos marcados, "mulher", "negro" e termos não marcados "homem" e "branco" ". Para o autor, a identidade só pode ser entendida como algo que é construído por meio da diferença.

Os marcadores sociais em determinado sentido estabelecem limites através dos quais os sujeitos constroem suas identidades, incidindo assim na sua produção. Posto isso, para compreender o processo de construção identitária é importante perceber que as diferenças raciais, como assinala Stuart Hall, "não nos constituem inteiramente, somos sempre diferentes e estamos sempre negociando diferentes tipos de diferenças - de gênero, sexualidade e de classe"ז2.

Identidade é algo em processo, permanentemente inacabado, e que se manifesta através da consciência da diferença e contraste com o outro, pressupondo, assim, a alteridade. Ou seja, "o sujeito se constrói a partir de marcas diferenciais provindas dos outros" ”3. Assim, a identidade é sempre construída em um processo de interação e de diálogo que estabelecemos com os outros.

Ora, o racismo dificulta o diálogo entre os diferentes grupos que compõe a sociedade brasileira, pois cria fronteiras simbólicas rígidas, estabelecendo binarismo identitários, ou seja, uma identidade do que é "ser negro" contraposta ao que é "ser branco", baseadas em estereótipos negativos para os primeiros e positivos para os últimos. O racismo é assim uma forma de negação ou de e mistificação da alteridade da população negra, fixando-a em estereótipos, atribuindo-lhe uma essência de inferioridade e maldade, não reconhecendo suas diferenças, infringindo-lhe o que Alberto Memmi chama de "a marca do plural" 4 .

O negro recebe a "marca" do estigma, tendo sua cor de pele utilizada como o principal elemento de estigmatização. Frantz Fanon ${ }^{15}$ já havia chamado esse processo de "esquema epidérmico" do sistema colonial, o arcabouço de discursos culturais, políticos e históricos de estigmatização do negro. Ele aponta que certas sociedades,

9 Cf. MELUCCI, Alberto. O jogo do Eu: a mudança de si em uma sociedade global. São Leopoldo Editora Unisinos, 2004 .

Io BRAH, Avtar. Diferença, diversidade e diferenciação. Cadernos Pagu, n. 26, jan.-jun. 2006.

II LACLAU, Ernesto, I990, p. 33 apud STUART, Hall. Op. cit., 2000, p. IIO.

I2 HALL, Stuart. Da diáspora: Identidade e mediações culturais. Trad. Adelaine La Guardiã Resende. Belo Horizonte/Brasília, Editora UFMG/Representação da UNESCO no Brasil, 2003, p. 346.

I3 NASCIMENTO, Elisa Larkin. O sortilégio da cor: identidade, raça e gênero no Brasil. São Paulo: Summus, 2003, p. 32.

I4 MEMMI, Alberto. Retrato do colonizador precedido pelo retrato do colonizado. Trad. Ronald Corbisier e Mariza Pinto Coelho. 2. ed. Rio de Janeiro: Paz e Terra, I977, p. 8I.

I5 FANON, Frantz. Pele negra, máscaras brancas. Trad. Renato Silveira. Salvador: Edufba, 2008. 
não só nas Américas, constroem discursos e significados que tentam reduzir o negro a uma cor, levando-o a elaborar um esquema corporal histórico-social de acordo com elementos fornecidos por um outro, o branco, e não por ele próprio. Conforme escreveu Frantz Fanon,

Elaborei, abaixo do esquema corporal, um esquema histórico-social. Os elementos que utilizei não me foram fornecidos pelos resíduos de sensações e percepções de ordem sobretudo táctil, espacial, cenestésica e visual, mas pelo outro, o branco, que os teceu para mim através de mil detalhes, anedotas, relatos ${ }^{\mathrm{I}}$.

A acentuação das características fenotípicas do negro, particularmente a cor da pele, aproximou a questão racial daquilo que Erving Goffman ${ }^{17}$ analisou como "teoria do estigma”. Izildinha B. Nogueira, em sua tese Significações do corpo negro ${ }^{\mathrm{I}}$, oferece elementos que permitem analisar o processo de estigmatização a que se encontram submetidos muitos sujeitos negros. A autora salienta que a rede de significações sobre o corpo negro foi formulada culturalmente, correspondendo à necessidade de se estabelecer um modelo do que é desejável. A partir desse modelo é que se constituiu socialmente sobre o "corpo negro" o repertório do execrável, ou seja, do inaceitável, ao mesmo tempo que se investiu a representação do "corpo branco" relacionando-o a atributos morais e intelectuais tidos como puros, belos e sagrados.

Assim rotulado socialmente, o corpo negro é inscrito como marca de identidade. Nessa perspectiva, como nos alerta Stuart Halli9, "negro" é transformado em uma categoria de essência. O significante "negro", assim como o "corpo negro", é racializado, desconsiderando-se a memória histórica, a diversidade, o contexto social e cultural.

Somos tentados a exibir o significante "negro" como um dispositivo que pode agregar a todos negros e negras, policiando as fronteiras políticas, simbólicas e posicionais como se fossem genéticas. [...] "Negro" não é uma categoria de essência numa direção à homogeneidade, existe um conjunto de diferenças históricas e experiências que devem ser consideradas e que localizam, situam e posicionam o povo negro ${ }^{20}$.

De acordo com Stuart Hall ${ }^{2 \mathrm{I}}$, a criação de significados corresponde em parte à tentativa dos seres sociais de criar mundos fixos e estáveis. No entanto, não se pode ter o controle sobre a existência de significados que surgem de maneira suplementar,

I6 Idem, p. I05.

I7 GOFFMAN, Erving. Estigma: notas sobre a manipulação da identidade deteriorada. Rio de Janeiro: Zahar, I978, p. I5.

I8 NOGUEIRA, Izildinha Beatriz. Significações do corpo negro. Tese de doutorado. São Paulo: Universidade de São Paulo, I998, p. 46.

I9 HALL, Stuart. Op. cit., 2003, p. 345. Grifos nossos.

20 Idem, p. 345.

2I Idem. A identidade cultural na pós-modernidade. Rio de Janeiro: DP\&A, 2006, p. II. 
subvertendo expectativas aparentemente estáveis. O significado, descreve ele, "é inerentemente instável: ele procura o fechamento (a identidade), mas ele é constantemente perturbado (pela diferença). Ele está constantemente escapulindo de nós"22.

A categorização do negro é uma tentativa de aprisioná-lo a uma alteridade forjada, a um lugar social que lhe impõe características de desacreditado. Ou seja, na relação social, a "marca" que lhe é impingida faz recair sobre ele um olhar de descrédito que impede que ele possa ser percebido pela totalidade de seus atributos e de forma individual ${ }^{23}$. Nota-se que a identidade pessoal é subsumida à identidade social. O que faz com que o sujeito negro seja compreendido de acordo com a essencialização de seu grupo étnico-racial. Nas palavras de Edith Piza: “[...] o lugar do negro é o lugar de seu grupo como um todo e do branco é o de sua individualidade. Um negro representa todos os negros. Um branco é uma unidade representativa apenas de si mesmo"24.

Serge Moscovici salienta que “[...] o racismo é o caso extremo em que cada pessoa é julgada, percebida, vivida, como representante de uma sequência de outras pessoas ou de uma coletividade" 25 . Assim, podemos dizer que socialmente com base em estereótipos se configura para o negro uma identidade coletivamente atribuída, definida por Kabengele Munanga ${ }^{26}$, como fruto da seleção de sinais diacríticos (atributos selecionados a partir do seu complexo cultural - religião, política, economia, artes, visão de mundo etc.), realizada pelo grupo opositor. Mas há ainda outra dimensão que faz parte do processo da construção da identidade, a dimensão da autoatribuição ou autodefinição, que se forma quando o próprio grupo seleciona sinais diacríticos para se autodefinir. Conforme o autor ${ }^{27}$, compreendemos que a identidade negra corresponde também à identidade de autoatribuição.

Quando falamos em uma identidade estereotipada, e atribuída ao negro, estamos nos referindo a algo forjado socialmente com intuito de inferiorizá-lo. Na sociedade brasileira, essa identidade foi formulada historicamente desde o período colonial, com base na inferiorização das diferenças impressas no corpo escravizado. Nilma Lino Gomes ${ }^{28}$ assinala, que a inferiorização do corpo negro foi um instrumento utilizado pelo regime escravista para justificar a reificação do homem negro e encobrir as intenções econômicas e políticas. Nesse contexto, segundo a autora, a comparação entre os sinais diacríticos do corpo negro, como a cor, o cabelo, o nariz e os sinais do corpo do branco europeu serviu de argumento para formulação de um

\footnotetext{
22 Idem, p.II.

23 GOFFMAN, Erving. Op. cit., p. I4.

24 PIZA, Edith. Porta de vidro: entrada da branquitude. In: CARONE, Iray; BENTO, Maria. A. S. (orgs.). Psicologia social do racismo: estudos sobre branquitude e branqueamento no Brasil. Petrópolis: Vozes, 2002, p. 72.

25 MOSCOVICI, Serge. A representação social da psicanálise. Rio de Janeiro: Zahar, I978, p. 64.

26 MUNANGA, Kabengele. Negritude e identidade negra ou afrodescendente: um racismo ao avesso?. Revista da ABPN, vol. 4, n. 8, 20I2, p. 9.

27 Idem, p. Io.

28 GOMES, Nilma Lino. Trajetórias escolares, corpo negro e cabelo crespo: reprodução de estereótipos ou ressignificação cultural?. Revista Brasileira de Educação, n. 2I, p. 40-5I, set.- dez. 2002, p. 42.
} 
padrão de beleza e de fealdade que persegue o grupo étnico-racial negro até os dias atuais. Assim, o corpo passa a ser expressão da identidade e as diferenças corporais são utilizadas para justificar a hierarquização social. Nessa perspectiva, a identidade atribuída ao negro é uma construção social que embora não corresponda à realidade, produz efeitos sobre ela, ou seja, embora tenha um caráter fictício quando presente no imaginário coletivo, orienta as relações entre negros e brancos na sociedade brasileira.

Ambas as dimensões da identidade atribuída ou de autoatribuição (identidade negra) são coletivamente construídas e se transfiguram conforme o contexto social, cultural e político. No entanto, a identidade atribuída é dotada exclusivamente de um caráter essencializador, na medida em que relações de poder estão envolvidas na essencialização do que é ser negro. Diferentemente, a identidade autoatribuída (identidade negra), não se configura em "uma essência, mas um posicionamento"29. Porém, não se pode negar que em seu percurso histórico de construção e reconstrução recorre a um certo "essencialismo estratégico" ${ }^{30}$, entendendo por isso uma relação com as diferenças que permita aos grupos estabelecerem referências de pertencimento e reconhecimento.

Conforme observa Lia Vainer Schucman ${ }^{31}$, indivíduos ou grupos sociais não trazem dentro de si uma essência negra ou branca, mas essas categorias podem ser ressignificadas conforme necessidade e contexto social. A autora assinala que ser negro não é uma entidade fixa e imutável. Todavia "[...] ser negro no Brasil é uma condição objetiva em que, a partir de um estado primeiro, definido pela cor de pele e pelo passado, o negro é constantemente remetido a si mesmo pelos outros"32. $\mathrm{Na}$ esfera individual de construção da identidade o negro, em uma sociedade racista, encontra-se à mercê das condições objetivas e do imaginário coletivamente construído com base em significações fixas negativas sobre o seu grupo étnico-racial.

Sob essa perspectiva, a identidade presente no imaginário social das pessoas, é diferente para o grupo étnico-racial negro e para o grupo étnico-racial branco. Ambas são mistificadas socialmente, mas de maneira distinta e contraposta. Na forma dominante, o branco é mistificado como expressão de superioridade e universalidade que dispensa especificações. Em contraposição, o negro é colocado no paradigma de inferioridade, expressão do que é exótico ou ruim. É construído para ele o mito do

29 HALL, Stuart. Identidade cultural e diáspora. Revista do Patrimônio Histórico e Artístico Nacional. Rio de Janeiro: Iphan, I996, p. 70.

30 Esse termo, utilizado por Gayatri Chakravorty Spivak, se refere à prática da essencialização das identidades como estratégia de grupos subalternizados, para obtenção de direitos. Cf. SPIVAK, Gayatri C. Pode o subalterno falar?. Trad. Sandra Regina Goulart Almeida, Marcos Pereira Feitosa e André Pereira. Belo Horizonte: Editora UFMG, 20I0.

3I SCHUCMAN, Lia Vainer. Entre o "encardido", o "branco" e o "branquíssimo": Raça, hierarquia e poder na construção da branquitude paulistana. Tese de doutorado. São Paulo: Universidade de São Paulo, 2oI2, p. 40.

32 Idem, p. 4I. 
negro, como assinalou Frantz Fanon ${ }^{33}$, através de fetiches - selvagem, analfabeto, estúpido, sensual, emotivo, dócil, entre outros.

Esse mito influencia no processo de percepção dos indivíduos, sejam eles brancos ou negros, e, portanto, no modo de construção de representações sociais. As representações têm a função de tornar familiar o que nos é estranho34. Quando uma representação é introduzida na subjetividade, ela será remodelada e reconstruída para relacionar-se e articular-se com outras representações. Stuart Hall compreende a identidade como ponto de "sutura", ou seja, encontro entre discursos e práticas sociais (nível social) e processos subjetivos (nível psíquico) - "As identidades são, pois, pontos de apego temporário às posições-de-sujeito que as práticas discursivas constroem para nós"35.

Ana Célia Silva ${ }^{36}$ salienta que o preconceito, os estereótipos e julgamentos prévios são objetos internalizados na consciência pela ideologia do recalque das diferenças e utilizados para construção da percepção social do negro - e essa construção é ao mesmo tempo objetiva e subjetiva. Entretanto, não é estanque: a representação de algo pode ser modificada e reconstruída a partir de elementos acrescentados ao longo do processo de reconstrução e remodelagem de objetos. Nesse sentido, conforme Ana Célia Silva sublinha, a representação social é ativa, constantemente reconstrói e remodela os dados vindos do exterior ${ }^{37}$ :

[...] transformar as representações sociais significa transformar os processos de formação de conduta em relação ao outro representado, bem como as relações com esse outro, porque na medida em que essas representações não apresentarem objetos de recalque e inferiorização desse outro, a percepção inicial e o conceito resultante dessa percepção, em nossa consciência, terá grande aproximação com o real ${ }^{8}$.

No que tange a relação entre racismo e subjetividade, Frantz Fanon, no livro Pele Negra, máscaras brancas ${ }^{39}$, já chamava a atenção para um ponto importante. Segundo ele, a subjetividade do negro é marcada por uma neurose capaz de gerar uma alienação da sua condição de sujeito negro, levando-o por vezes a se pensar no mundo dos brancos. Ressaltamos que esta situação não é fruto de algo inerente ao negro, mas consequência histórica do processo complexo de construção identitária em que se estabelece essa referência ambivalente - a de pensar-se socialmente no mundo dos brancos.

33 FANON, Frantz. Op. cit., p. Io9.

34 MOSCOVICI, Serge. Op. cit., p. 63.

35 HALL, Stuart. Op. cit., 2000, p. II2.

36 SILVA, Ana Célia da. A representação social do negro no livro didático: o que mudou? Por que mudou? Salvador: Edufba, 20II, p. 29 e ss.

37 Idem, p. 30-3I.

38 Idem, p. 3I.

39 FANON, Frantz. Op. cit. 
[...] o negro vive uma ambiguidade extraordinariamente neurótica. Com vinte anos, isto é, no momento em que o inconsciente coletivo é mais ou menos perdido, ou pelo menos difícil de ser mantido no nível consciente, o antilhano percebe que vive no erro. Por quê? Apenas porque, e isso é muito importante, o antilhano se reconheceu como preto, mas, por uma derrapagem ética, percebeu (inconsciente coletivo) que era preto apenas na medida em que era ruim, indolente, malvado, instintivo. Tudo o que se opunha a esse modo de ser preto, era branco. Deve-se ver nisso a origem da negrofobia do antilhano. No inconsciente coletivo, negro = feio, pecado, trevas, imoral. Dito de outra maneira: preto é aquele que é imoral. Se, na minha vida, me comporto como um homem moral, não sou preto. Daí se origina o hábito de se dizer na Martinica, do branco que não presta, que ele tem uma alma de preto. A cor não é nada, nem mesmo a vejo, só reconheço uma coisa, a pureza da minha consciência e a brancura da minha alma $4^{\circ}$.

Na sociedade brasileira, essa ambiguidade é especialmente acentuada devido ao caráter peculiar do racismo brasileiro, marcado pelo ideal do branqueamento e pelo mito da democracia racial. A dificuldade de se pensar a questão racial está ligada ao processo de desmemorização das vicissitudes históricas da diáspora africana, principalmente daquelas relacionadas à construção da identidade negra no Brasil. Para o racismo norte-americano, vigente até pouco tempo atrás, pessoas de pele clara que tivessem ancestrais africanos eram consideradas negras, e as crianças que nasciam de uniões inter-raciais não eram reconhecidas como mestiças. Nos censos estadunidenses, de I930 até I960, a categoria “black” abrangia a todos, não importando a ancestralidade longínqua ou a tonalidade da pele. Já no Brasil, como já é clássico desde a análise de Oracy Nogueira ${ }^{4 \mathrm{I}}$, a pele clara somada a outros traços corporais possibilitam a uma pessoa de ascendência africana se afirmar como branca. Ao lado disso, de uma forma ou de outra, a mestiçagem foi reconhecida, primeiro repudiada, depois elevada à condição de mito nacional. No seu livro Relativizando: uma introdução à Antropologia Social, Roberto DaMatta chama de "triângulo das raças" o mito que levou tanto intelectuais como homens comuns a conceber a sociedade brasileira como unificada por laços inter-raciais. Nessa metáfora, o branco estaria no ângulo superior do triângulo, os negros e os índios nos ângulos da base, sempre abaixo e sistematicamente submetidos. Esse mito permitiu que se olhasse como unidade uma sociedade profundamente desigual no plano político e econômico e explicitamente hierarquizada no plano racial ${ }^{42}$.

A fábula da democracia racial dissimula tensões raciais e cria a ilusão de inclusão, silenciando vozes que denunciam a violência real e simbólica, construindo, de muitas formas, tanto lugares de privilégio quanto de exclusão e discriminação. As estigmatizações e humilhações sociais cotidianas, explicitas ou implícitas, sutis

40 Idem, p. I62.

4I NOGUEIRA, Oracy. Preconceito racial de marca e preconceito racial de origem: sugestão de um quadro de referência para a interpretação do material sobre relações raciais no Brasil. Tempo Social, vol. I9, n. I, p. 287-308, 2007.

42 DAMATTA, Roberto. Digressão: a fábula das três raças ou o problema do racismo à Brasileira. In: Relativizando: uma introdução a antropologia social. 3. ed. Petrópolis: Vozes, I983, p. 58-85. 
ou veladas, levam muitas vezes à formação de uma identidade negra ambígua e fragmentada. $\mathrm{O}$ ideal do branqueamento conduz alguns negros ao paradoxo instalado em sua subjetividade - a desejar tudo aquilo que representa a sua negação, ou seja, a brancura.

\begin{abstract}
"Ser branco" tanto quanto "ser negro", para além da tonalidade que reveste o corpo dos seres humanos, representam “valores”, significados. Para além do branco está a brancura, e tudo quanto essa condição de branco "simbolicamente” representa para o negro43.
\end{abstract}

Izildinha Nogueira 44 analisa o processo de alienação histórica dos negros brasileiros diante de seu próprio corpo. Assim, por vezes os negros são levados ao ódio com relação ao seu corpo e à sua condição, enveredando-se em um processo de autodestruição que se inicia pelo "apagamento" de marcas físicas (branqueamento físico, mutilações, entre outros) e psíquicas (negação de sua condição física de negro). Passam assim por um processo de pseudomorfose ${ }^{45}$, ou seja, de aquisição de uma "falsa identidade" que não representa o que são verdadeiramente. Trata-se da constituição de uma "identidade rotulada"46 que se estabelece mediante a anulação da "capacidade autônoma de identificação, produzindo uma internalização do estigma [...] imposto socialmente"47. Estigma que impede o negro de desenvolver um sentimento de pertencimento racial e, paralelamente, de construir a autoestima baseada numa identidade racial positiva.

Diante do que foi apresentado até o momento, é possível destacar que a construção, reconstrução do "ser negro" passa pela forma como o grupo étnico-racial negro foi e é representado socialmente, pois as representações são fundamentais para a construção, reconstrução ou ressignificações das identidades individuais ou de grupo. Como já salientamos, as representações sociais podem ser transformadas, modificando a forma como os indivíduos se percebem ou se conceituam.

\title{
A ESCOLA E A IDENTIDADE NEGRA
}

Considerando essa perspectiva, o Movimento Negro brasileiro vem trabalhando para que a representação social do negro seja revista, em todos os contextos sociais, mas sobretudo na escola. A escola passa a ser vista como principal espaço de

\footnotetext{
43 NOGUEIRA, Izildinha Beatriz. Op. cit., p. $\amalg 6$.

44 Idem, p. IO2.

45 O termo "pseudomorfose” é entendido aqui conforme a definição de Theodor W. Adorno, que a compreende como forma e expressão de alienação. Nas palavras do autor: "a pseudomorfose a uma forma alienada é, ela própria, a mesma coisa que expressão de alienação” (ADORNO, I996, p. I60, apud DUARTE, Rodrigo. Sobre o conceito de "pseudomorfose" em Theodor Adorno. Artefilosofia, n. 7, p. 3I- 40, 2009).
}

46 MELUCCI, Alberto. Op. cit.

47 Idem, p. 5 I. 
desconstrução de fixações, termos e conceitos construídos historicamente, por ser ambiente privilegiado de trocas culturais e de vivências entre indivíduos oriundos de diferentes grupos étnico-raciais. Portanto, lugar onde compartilhamos não só conteúdos e saberes escolares, mas também valores e crenças relativos à raça, gênero e classe social ${ }^{48}$. Para Nilma Lino Gomes,

A escola, enquanto instituição social responsável pela organização, transmissão e socialização do conhecimento e da cultura, revela-se como um dos espaços em que as representações negativas sobre o negro são difundidas. E por isso mesmo ela também é um importante local onde estas podem ser superadas 49 .

Nesse sentido, depreende-se a importância do debate educacional, pois a escola é importante esfera para enfrentamento e combate ao racismo. Segundo Ilma Fátima de Jesus,

A contribuição que o debate acerca da educação traz para o processo de reação à violência racial começa ao se denunciar a seletividade do modelo educacional vigente, o reforço aos valores da classe dominante, a perpetuação de uma prática pedagógica racista, que exclui o patrimônio cultural da população negra dos currículos escolares e o afastamento das classes populares (negras em sua maioria) do processo de ensino e aprendizagem ${ }^{50}$.

O processo de reação à violência racial ganha expressão no Movimento Negro brasileiro, em luta histórica pela desconstrução da visão estereotipada a respeito da história e cultura africana e afro-brasileira ${ }^{51}$. Uma vez cristalizadas e difundidas no ambiente escolar, estas construções preconceituosas são internalizadas e legitimadas, deturpando a formação de negros e brancos. Embora a discriminação e o preconceito atinjam a negros e brancos, e a questão da formação na cultura africana e afro-brasileira não seja interesse apenas dos negros, é preciso notar que o impacto da discriminação é diferenciado para aquele que discrimina e para aquele que é discriminado. Marilene Paré52 em estudo sobre autoimagem e autoestima na criança negra, salienta esta diferença. Segundo a autora, a criança branca desenvolve sentimento de autoestima e autoconfiança, enquanto na criança negra emerge sentimento de baixa autoestima e vergonha de ser negro.

O recalque das raízes culturais africanas na escola impossibilita a presença para

48 GOMES, Nilma Lino. Op. cit., p. 40.

49 Idem. Cultura negra e educação. Revista Brasileira de Educação, n. 23, p. 75-85, maio-ago. 2003, p. 77.

50 JESUS, Ilma Fátima de. O pensamento do MNU - Movimento Negro Unificado. In: SILVA, Petronilha Beatriz Gonçalves e BARBOSA, Lucia Maria de Assunção (orgs.). O pensamento negro em educação no Brasil: expressões do movimento negro. São Carlos Editora da UFSCar, I997, p. 47. Grifos nossos.

5 I Idem, p. 42 ess.

52 PARÉ, Marilene Leal. Auto-imagem e auto-estima na criança negra: um olhar sobre o seu desempenho escolar. Dissertação de mestrado. Porto Alegre: Pontifícia Universidade Católica do Rio Grande do Sul, 2000. 
os alunos negros, nesse contexto, não só de inserção numa história coletiva como de elementos de identificação positivos ${ }^{53}$. Suas origens étnicas ou não são representadas ou aparecem de maneira folclórica, unilateral e deturpada.

Num país cujos donos do poder descendem de escravizadores, a influência nefasta da escola se traduz não apenas na legitimação da situação de inferioridade dos negros, como também na permanente recriação e justificação de atitudes e comportamentos racistas. De outro lado, a inculcação de imagens estereotipadas induz a criança negra a inibir suas potencialidades, limitar suas aspirações profissionais e humanas e bloquear o pleno desenvolvimento de sua identidade racial54.

A luta do Movimento Negro resultou na formulação de políticas públicas voltadas para promoção da igualdade racial. Entre tais políticas públicas, sobretudo no campo educacional, temos a lei n. Io.639/2003 e a lei n. II.645/2008, que tratam da obrigatoriedade do ensino da história e cultura africana, afro-brasileira e indígena nos sistemas de ensino de educação básica, públicos e privados ${ }^{55}$. No processo de afirmação identitária, a revalorização das culturas africanas constitui-se em pilar para a identidade negra, pois pode servir para desconstruir representações que alienam a pessoa negra de seu próprio corpo e suas raízes étnico-raciais.

Petronilha B. da Silva chama de "africanidades brasileiras [...] de um lado os modos de ser, viver, de organizar suas lutas, próprios dos negros brasileiros, e de outro lado, as marcas da cultura africana que, independente da origem étnica de cada brasileiro,

53 Elisa Larkin Nascimento, no livro O sortilégio da cor: identidade, raça e gênero no Brasil, compreende o processo de formação de identidade como um fluxo de identificações, ou seja, um "conjunto de referenciais de que dispõe o indivíduo para medir suas ações e orientar suas atitudes perante si mesmo, aos outros e à sociedade” (Op. cit., p. 32). Essa autora ressalta que a construção da identidade negra autorreferenciada só será possível a partir de elementos capazes de remeter as identificações dos afro-brasileiros às raízes africanas. Assim, entendemos que, segundo a autora, a construção de uma identidade positiva entre os afro-brasileiros passaria por um processo de valorização da cultura negra e de diferentes etnias africanas.

54 Manifesto fruto da "Marcha Zumbi dos Palmares contra o racismo, pela cidadania e a vida", realizado pelo Movimento Negro no dia 20 de novembro de I995. Esse documento, entregue ao então presidente Fernando Henrique Cardoso, continha propostas e reivindicações de combate ao racismo, discriminação racial e as desigualdades sociais. $\mathrm{O}$ trecho expressa a necessidade de reforma e revisão dos currículos escolares, uma das reivindicações do Movimento Negro na esfera da educação. Cf. ROSEMBERG, Fúlvia. A criança pequena e o direito à creche no contexto dos debates sobre infância e relações raciais. In: Educação infantil, igualdade racial e diversidade infantil: aspectos políticos, jurídicos, conceituais. BENTO, Maria Aparecida Silva (org.). São Paulo: Centro de Estudos das Relações de Trabalho e Desigualdades (CEERT), 20I2, p. 33. Disponível em: <http://portal.mec.gov.br/index.php?option=com_docman\&view=download\&alias=II283educainfantisconceituais\&category_slug=agosto20I2pdf\&Itemid=30I92 >. Acesso em: 23 mar 2016.

55 A lei n. II.645, de Io de março de 2008, altera a lei n. 9.394, de 20 de dezembro de I996, modificada pela lei n. Io.639, de 9 de janeiro de 2003, que estabelece as diretrizes e bases da educação nacional, para incluir no currículo oficial da rede de ensino a obrigatoriedade da temática "História e Cultura Afro-Brasileira e Indígena”. 
fazem parte do seu dia-a-dia" ${ }^{6}$. Uma educação que favoreça essas africanidades pode contribuir para a reconstrução histórica da resistência do povo negro no Brasil. Essa luta produziu uma cultura que não nega sua raiz africana, mas inicia, a partir desta, outras condições de reelaborações culturais, além de proporcionar a manifestação de diferenças ${ }^{57}$. Em referências às ideias de Stuart Hall ${ }^{8}$, a respeito da manifestação da diferença e dos aspectos culturais, São Bernardo59, nota que o respeito às diferenças:

[...] pressupõe um respeito às culturas populares que guardam identidades civilizatórias imprescindíveis para a construção da identidade étnica. Entretanto, o autor [Stuart Hall] reconhece que o pós-modernismo, mesmo elevando os espaços das diferenças, contrariando o sentido da modernidade, ainda postula enunciados e valores eurocêntricos, merecendo atentar para o significado das tradições, estética, experiências e contra narrativas negras que se pretende expressar em linguagens não assimiladas ${ }^{60}$.

O sentido de educar abrindo-se para africanidades é primordial por permitir um diálogo transformador e humanizador. Abrir-se para as africanidades permite a todos, e não só aos negros, a aquisição de conhecimentos calcados na tradição e na memória, e assim estabelecer um contraponto à cultura eurocêntrica presente na escola. Permite corrigir as distorções "da cultura forjada pelas histórias oficiais, particularmente presentes [...] na história dos vencedores" ${ }^{\prime \prime}$, segundo Aloisio Jorge de Jesus Monteiro. Para esse autor, a cultura das identidades e suas experiências históricas de lutas vividas são resgatadas pela memória e transmitida pela narração de histórias que sobrevivem fazendo "os diversos atores do presente (re) conhecerem-se, então, como interlocutores fundamentais por e para outros sujeitos históricos" ${ }^{2}$.

Se presentes no conteúdo dos currículos escolares, as africanidades podem "desestabilizar a rigidez da lógica eurocêntrica, cristã, masculina, branca e heterossexual" "63 , contrapondo-a e fazendo dialogar com outras formas de ver o mundo. Pois as produções da cultura negra possibilitam o aprofundamento das

56 SILVA, Petronilha Beatriz Gonçalves. Aprendizagem e ensino das africanidades brasileiras. In: MUNANGA, Kabengele (org.). Superando o racismo na escola. Brasília: BMEC/Secretaria de Educação Fundamental/MEC/ UNESCO, 2000, p. I5I.

57 COSTA, Sidiney Alves. Militância do Movimento Negro na formação de professores em direitos humanos. Revista Segurança Urbana e Juventude, vol. I, n. I, 2008.

58 HALL, Stuart. Op. cit., 2003.

59 SÃO BERNARDO, Augusto Sergio dos Santos. Identidade racial e direito à diferença Xângo e Thémis. Brasília. Dissertação de mestrado. Brasília: Universidade de Brasília, 2006.

60 Idem, p. I52.

6I MONTEIRO, Aloisio Jorge de Jesus. Fronteira, cultura e exclusão: debates do nosso tempo. Border, Culture, Exclusion; Contemporary Issues, n. 3I, p. II9-I28, jan.-jun. 20II.

62 Idem, p. I24.

63 MOREIRA, Antônio Flávio Barbosa. A recente produção científica sobre currículo e multiculturalismo no Brasil (I995-2000): Avanços, desafios e tensões. Revista Brasileira de Educação, n. I8, set.-dez. 200I, p. 76. 
questões teóricas acerca da vida social, por proporcionar olhares, perspectivas e valores que libertam e não aprisionam. O estudo das africanidades possibilita novas formas de sociabilidade, desconstruindo valores que imobilizam, abrindo espaço para construção de ações libertadoras ${ }^{64}$.

Desse modo, a promulgação das leis n. I0.639/2003 e n. II.645/2008 sinalizou a possibilidade de mudança no imaginário pedagógico, na medida em que rompeu com o silêncio ou escamoteamento da história de desrespeito a negros e índios, reposicionando estes sujeitos no território escolar. Foi esse o sentido simbólico assinalado pela relatora do projeto da lei n. Io.639/2003, Petronilha B. Gonçalves e Silva na comemoração do aniversário de dez anos de sua aprovação pelo Congresso Nacional. Valor simbólico que se sustenta apesar dos entraves encontrados na implementação da lei ${ }^{65}$. Nesse sentido, o debate então inaugurado assinala uma nova perspectiva de educação, ao exigir um repensar sobre as relações étnico-raciais no espaço escolar, com todas suas nuances e complexidades. Essa discussão traz em seu bojo tanto uma nova reflexão sobre a educação formal quanto novas possibilidades de se conceber o currículo. Entre elas, a invenção de uma escola capaz de representar e trabalhar a pluralidade cultural brasileira, ou seja, constituí-la sob uma perspectiva multicultural. Enfim, uma escola propagadora de uma pedagogia desmistificadora, capaz de contribuir com a construção positiva da identidade negra. Assim a descreve Neusa Santos Souza:

Ser negro é, além disto, tomar consciência do processo ideológico que, através de um discurso mítico acerca de si, engendra uma estrutura de descobrimento que o aprisiona numa imagem alienada, na qual se reconhece. Ser negro é tomar posse desta consciência e criar uma nova consciência que reassegure o respeito às diferenças e que reafirme uma dignidade alheia a qualquer nível de exploração. Assim, ser negro não é uma condição dada, a priori, é um vir a ser. Ser negro é tornar-se negro ${ }^{66}$.

Nesse sentido, nota-se que a reconstrução do "ser negro" passa por um processo de conscientização e valorização da negritude e pela construção política e sociocultural de sua identidade. Segundo Nilma Lino Gomes, reconhecer-se numa identidade "supõe, portanto, responder afirmativamente a uma interpelação e estabelecer um sentido de pertencimento a um grupo de referência" ${ }^{\prime 7}$. Assim, uma escola apta a favorecer as diferenças e o diálogo entre os indivíduos de diferentes grupos étnico-raciais permite, ao educando negro, desconstruir estereótipos e preconceitos em relação à sua origem e adquirir sentimento de pertença, que pode conduzi-lo a atuar em defesa dos valores de seu grupo étnico-racial. A escola não pode ser espaço de alienação da negritude e de expropriação do corpo negro, mas espaço que

\footnotetext{
64 COSTA, Sidiney Alves. Op. cit.

65 Cf. SILVA, Petronilha Beatriz Gonçalves. Aula pública "Chegando aos Io anos: a lei Io.639 e os desafios da superação do racismo na educação. Formação em Direitos Humanos Ação Educativa”, s.d.

66 SOUZA, Neusa Santos. Tornar-se negro. Rio de Janeiro: Graal, I983, p. 77.

67 GOMES, Nilma Lino. Educação, identidade negra e formação de professores/as: um olhar sobre o corpo negro e o cabelo crespo. Educação e Pesquisa, vol. 29, n. I, jan.-jun. 2003, p. I7I.
} 
valorize a autenticidade e originalidade extirpadas pelo racismo. A escola pode assim possibilitar ao aluno negro um questionamento sobre o seu corpo que não o leve a tentativa de fazer-se branco, mas de tornar-se negro.

\section{CONSIDERaÇões Finais}

A complexidade das representações acerca da população negra indica um arcabouço formulado historicamente no sentido de vigiar seu corpo, aprisioná-lo em uma identidade atribuída socialmente, construída por uma rede de significações que nada mais são além de armas inventadas com intuito de preservar hierarquias sociais. As violências físicas e simbólicas criam dificuldades à formação de sentimento de pertencimento racial, fortalecendo obstáculos ao seu posicionamento político. É importante destacar que as representações negativas sobre a população negra prejudicam as relações étnico-raciais entre negros e não negros ocasionando deturpação em suas identidades individuais e de grupo.

A escola se constitui em espaço privilegiado de formação identitária, sendo assim lócus importante de intervenção nos rumos da construção da identidade negra. Ao não reconhecer os saberes das diversas culturas presentes no seu interior, a escola elimina saberes e legitima as práticas hegemônicas de exclusão. Ao não dar voz a todos os saberes, a escola não reconhece os alunos como sujeitos socioculturais fruto de diversas experiências.

Podemos dizer que atualmente houve uma ampliação considerável com relação ao debate acerca das diferenças e combate ao racismo na sociedade brasileira. No entanto, mesmo após a sua inclusão, a lei n. 10.639/2003 ainda encontra dificuldades para sua concretização no âmbito escolar, pois ainda se considera que a lei só interessa aos negros, considerados erradamente como parcela, e não maioria, da população brasileira. Além disso, infelizmente não são muitos os espaços que se abrem a discussões em torno da diversidade e do combate à discriminação e preconceito racial. As diferenças ainda são vistas com desconfiança, e o racismo permanece sob a imagem de um mostro adormecido sobre o qual não se pode falar para que não seja despertado. Ou seja, o silêncio ainda é visto como defesa e não como viabilizador de preconceitos e discriminações. As leis n. I0.639/2003 e sua versão modificada como lei n. II.645/2008 devem ser interpretadas de modo que sua aplicação não seja vista apenas como acréscimo de conteúdo ou disciplinas especificas. Há uma necessidade de releitura de disciplinas, de conteúdo, de posturas, de paradigmas, de visões sobre o currículo, pois este não se restringe apenas a conteúdos, mas a práticas, elementos e experiências compartilhadas cotidianamente pelos sujeitos no universo escolar.

Acreditamos na possibilidade de mudança desta realidade opressiva a que estão submetidos os afro-brasileiros, principalmente mediante uma educação que possibilite a afirmação da identidade negra de forma positiva. Sabemos o quanto ainda devemos lutar para consolidar os espaços educativos, enquanto meios de desmitificação e promoção da equidade entre pessoas pertencentes aos mais diversos grupos étnico-raciais formadores da sociedade brasileira. No entanto, sabemos que este percurso de reconstrução e esclarecimento está atravessado por nossas 
vivências, mediante as quais podemos reconstruir a nossa consciência do eu com o outro.

\section{SOBRE AS AUTORAS}

VIVIANE BARBOZA FERNANDES é doutoranda no programa de pós-graduação da Faculdade de Educação da Universidade de São Paulo (FE-USP). Graduada em Ciências Sociais e mestre em educação escolar pela Universidade Estadual Paulista (Unesp). Bolsista do Programa Mestrado e Doutorado - Programa de Formação Continuada de Educadores da Secretaria da Educação do Estado de São Paulo. E-mail: vibf@usp.br.

\section{MARIA CECILIA CORTEZ CHRISTIANO DE SOU-}

ZA é professora titular do Departamento de Filosofia da Educação e Ciências da Educação da Faculdade de Educação da Universidade de São Paulo. Orientadora e coordenadora do grupo de pesquisa dedicado às relações étnico-raciais na educação brasileira no Programa de Pós-graduação da Faculdade de Educação da Universidade de São Paulo. E-mail: mcccs@usp.br. 


\section{REFERÊNCIAS BIBLIOGRÁFICAS}

BUTLER, Judith. Corpos que pesam: sobre os limites discursivos do “sexo”. In: LOURO, Guacira Lopes (org.). O corpo educado: pedagogias da sexualidade. Belo Horizonte: Autêntica, 2000.

BRAH, Avtar. Diferença, diversidade e diferenciação. Cadernos Pagu, n. 26, jun. 2006. Disponível em: <http://goo.gl/66qYHh〉. Acesso em: 2I dez. 20I4.

COSTA, Sidiney Alves. Militância do Movimento Negro na formação de professores em direitos humanos. Revista Segurança Urbana e Juventude, vol. I, n. I, 2008. Disponível em: 〈http://goo.gl/xFWQYN $\geq$. Acesso em: I2 dez. 2008.

DAMATTA, Roberto. Digressão: a fábula das três raças ou o problema do racismo à Brasileira. In: Relativizando: uma introdução a antropologia social. 3. ed. Petrópolis: Vozes, I983.

DUARTE, Rodrigo. Sobre o conceito de "pseudomorfose" em Theodor Adorno. In: Artefilosofia, n. 7, p. 3I- 40, 2009. Disponível em: 〈http://goo.gl/u4IxhU〉. Acesso em: Io fev. 2016.

FANON, Frantz. Pele negra, máscaras brancas. Trad. Renato Silveira. Salvador:

Edufba, 2008.

GOFFMAN, Erving. Estigma: notas sobre a manipulação da identidade deteriorada. Rio de Janeiro: Zahar, I978.

GOMES, Nilma Lino. Cultura negra e educação. Revista Brasileira de Educação, n. 23, maio-ago. 2003. Disponível em: <http://goo.gl/rRxs9M 2 . Acesso em: Io fev. 2016.

. Educação, identidade negra e formação de professores/as: um olhar sobre o corpo negro e o cabelo crespo. In: Educação e Pesquisa, vol. 29, n. I, jan.-jun. 2003. Disponível em: 〈http://goo.gl/5rmIBn之. Acesso em: Io fev. 2016.

. Trajetórias escolares, corpo negro e cabelo crespo: reprodução de estereótipos ou ressignificação cultural?. Revista Brasileira de Educação, n. 2I, set.-dez. 2002. Disponível em: 〈http://goo.gl/ltQVrD〉. Acesso em: 06 fev. 2016.

GUIMARÃES, Antônio Sergio Alfredo. Como trabalhar com "raça" em Sociologia. Educação e Pesquisa, vol. 29, n. I, 2003.

HALL, Stuart. Identidade cultural e diáspora. In: Revista do Patrimônio Histórico e Artístico Nacional. Rio de Janeiro: Iphan, I996.

. The Work of Representation. In: . (Org.). Representation, Cultural Representations and

Signifying Practices. Londres/Nova Deli: Thousands Oaks/Sage, I997. Disponível em: <http://goo. gl/68WJUn>. Acesso em: Io fev. 2016.

Quem precisa de identidade?. In: SILVA, Tomaz Tadeu (org.). Identidade e diferença: a perspectiva dos Estudos Culturais. Petrópolis: Vozes, 2000

.Da diáspora: identidade e mediações culturais. Trad. Adelaine La Guardiã Resende. Belo Horizonte/ Brasília: Editora UFMG/Representação da UNESCO no Brasil, 2003.

A identidade cultural na pós-modernidade. Rio de Janeiro: DP\&A, 2006.

JESUS, Ilma Fátima de. O pensamento do MNU - Movimento Negro Unificado. In: SILVA, Petronilha Beatriz Gonçalves e BARBOSA, Lucia Maria de Assunção (orgs.). O pensamento negro em educação no Brasil: expressões do movimento negro. São Carlos: Editora da UFSCar, I997.

LACLAU, Ernesto. New Reflections on the Revolution of our Time. Londres: Verso, I990.

LOURO, Guacira Lopes (org.). Pedagogias da sexualidade. In: . O corpo educado: pedagogias da sexualidade. Belo Horizonte: Autêntica, 2000.

MELUCCI, Alberto. O jogo do Eu: a mudança de si em uma sociedade global. São Leopoldo, Editora Unisinos, 2004 . 
MEMMI, Albert. Retrato do colonizador precedido pelo retrato do colonizado. Trad. Ronald Corbisier e Mariza Pinto Coelho. 2. ed. Rio de Janeiro: Paz e Terra, I977.

MONTEIRO, Aloisio Jorge de Jesus. Fronteira, cultura e exclusão: debates do nosso tempo. Border, Culture, Exclusion; Contemporary Issues, n. 3I, jan.-jun. 20II. Disponível em: 〈http://goo.gl/qXwb8A $\rangle$. Acesso em: 24 ago. 2016.

MOREIRA, Antônio Flávio Barbosa. A recente produção científica sobre currículo e multiculturalismo no Brasil (I995-2000): avanços, desafios e tensões. Revista Brasileira de Educação, n. I8, p. 65-8I, set.-dez. 200I. Disponível em: 〈http://goo.gl/ltcZOm〉. Acesso em: Io fev. 2016.

MOSCOVICI, Serge. A representação social da psicanálise. Rio de Janeiro: Zahar, I978.

MUNANGA, Kabengele. Identidade, cidadania e democracia: algumas reflexões sobre os discursos anti-racistas no Brasil. In: Resgate, n. 6, I996.

. Negritude e identidade negra ou afrodescendente: um racismo ao avesso? Revista da ABPN, vol. 4, n. 8, 20I2. Disponível em: 〈http://goo.gl/7ZdCs7〉. Acesso em: 25 jun. 20I4.

NASCIMENTO, Elisa Larkin. O sortilégio da cor: identidade, raça e gênero no Brasil. São Paulo: Summus, 2003.

NOGUEIRA, Izildinha Beatriz. Significações do Corpo Negro. Tese de doutorado. São Paulo: Universidade de São Paulo, I998.

NOGUEIRA, Oracy. Preconceito racial de marca e preconceito racial de origem: sugestão de um quadro de referência para a interpretação do material sobre relações raciais no Brasil. Tempo Social, vol. I9, n. I, 2007. Disponível em: 〈http://goo.gl/7FgZ7a. Acesso em: 9 fev. 2016.

PARÉ, Marilene Leal. Auto-imagem e auto-estima na criança negra: um olhar sobre o seu desempenho escolar. Dissertação de mestrado. Porto Alegre: Pontifícia Universidade Católica do Rio Grande do Sul, 2000.

PIZA, Edith. Porta de vidro: entrada da branquitude. In: CARONE, Iray e BENTO, Maria Aparecida Silva (orgs.). Psicologia social do racismo: estudos sobre branquitude e branqueamento no Brasil. Petrópolis: Vozes, 2002.

SÃO BERNARDO, Augusto Sergio dos Santos. Identidade racial e direito à diferença Xângo e Thémis. Brasília. Dissertação de mestrado. Brasília: Universidade de Brasília, 2006. Disponível em: <http:// goo.gl/hp6lhD >. Acesso em: Io fev. 2016.

SCHUCMAN, Lia Vainer. Entre o "encardido", o "branco" e o "branquíssimo": Raça, hierarquia e poder na construção da branquitude paulistana. Tese de doutorado. São Paulo: Universidade de São Paulo, 2012.

SILVA, Ana Célia da. A representação social do negro no livro didático: o que mudou? Por que mudou?. Salvador: Edufba, 20II.

SILVA, Petronilha Beatriz Gonçalves. Aprendizagem e Ensino das Africanidades Brasileiras. In: MUNANGA, Kabengele (org.). Superando o Racismo na Escola. Brasília: BMEC-Secretaria de Educação Fundamental/MEC/UNESCO, 2000.

. Aula pública "Chegando aos ıo anos: a lei 1o.639 e os desafios da superação do racismo na educação. Formação em Direitos Humanos Ação Educativa”, s.d. Disponível em: 〈http://goo.gl/cPoAoE〉. Acesso em: 09 fev. 2016.

SOUZA, Neusa Santos. Tornar-se negro. Rio de Janeiro: Graal, I983.

SPIVAK, Gayatri Chakravorty. Pode o subalterno falar?. Trad. Sandra Regina Goulart Almeida, Marcos Pereira Feitosa e André Pereira. Belo Horizonte: Editora UFMG, 2010. 